\title{
Scientists moving into sales
}

\author{
Ann Pinn
}

Many scientists find bench work unrewarding after some years spent in the laboratory and if there are no prospects of promotion - especially in the research environment - they may consider moving to a technical sales career.

FAR from being “just an option", a career step for a scientist into sales should be considered very carefully indeed. It is true to say that sales is a vocation and more of a way of life than a nine-to-five job. Salespeople often work very long hours and travel extensively; they need to be lively, enthusiastic and even-tempered at all times - not always an easy task. But most important of all is an empathy with the customers they visit, and if the salesperson's background is in the laboratory a rapport and understanding can often be established quickly.

This is why scientists have the favoured background for sales of consumables and equipment into this industry; their knowledge and interest can capture the customer's attention.

The rewards in this type of career can be great and are not just monetary. It can be very satisfying to solve someone's problem, to recognize and implement a new technique or improve an old one, to persuade someone to try a new kit or purchase an instrument.

Should the scientist decide in favour of a move into sales, how to go about it? Primarily the following questions should be asked:

- Why do I want to go into sales?

- What qualities do I have to enable me to be successful?

- What preparation/homework do I need to do?

If the answer to the first question is "because I am bored in the laboratory and do not know what else to do", perhaps this career is not suitable.

If the answer to the second is "I like meeting people", this could be a tentative start but certainly not the whole picture.

Companies are looking for individuals who relish a challenge, are self-motivated and are looking for success and recognition. For people who fit these criteria, there are various options, well known but worth reiterating:

- Contacting companies direct to see if they have any vacancies.

- Looking through the scientific journals for job opportunities.

- Contacting a recruitment consultant.

While all of these methods should be used for thoroughness, the first one can be tedious, yet a recruitment agency can make it less so by reaching a great number of companies at any one time. Also, many jobs are not advertised but registered with agencies.

An agency should be chosen that specializes in scientific and technical recruitment; a fast-moving, high-street agency may not be sympathetic to a scientist's needs, nor understand the technology involved; after all, double glazing and insurance sales undoubtedly will not appeal.

A professional agency will want to see a $\mathrm{CV}$ and to meet the person face-to-face, to place them in an interview situation similar to the one they will face with a future employer. The prospective salesperson can expect tough questioning and would be wise to analyse their own strengths, weaknesses and ambitions before inter-

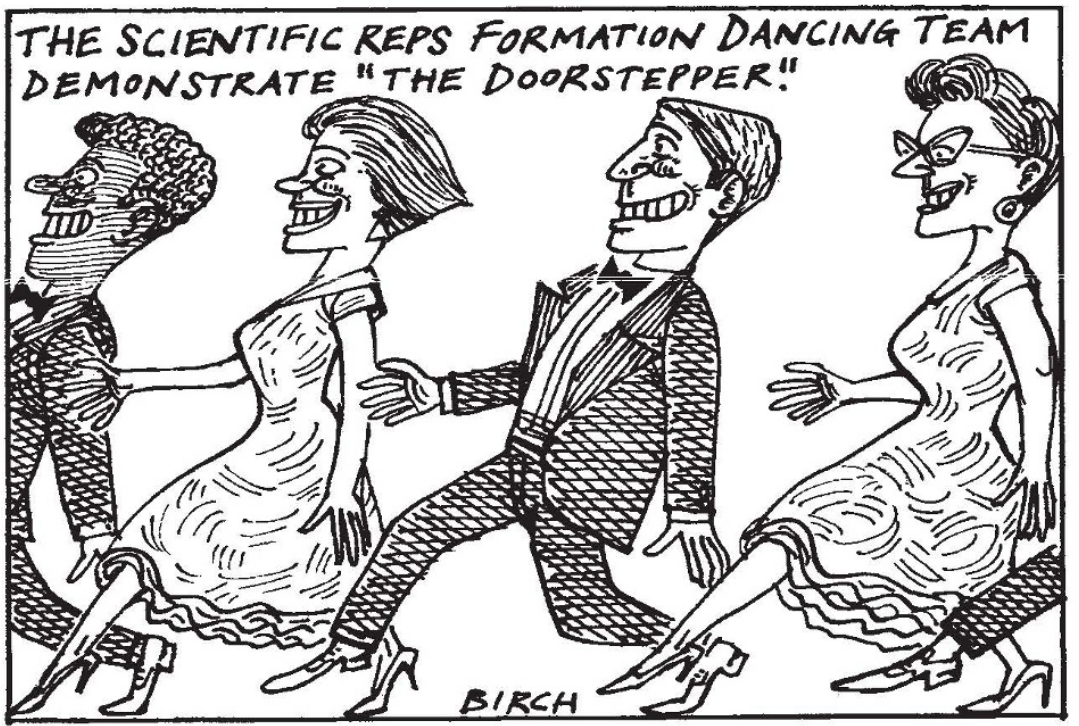

\section{What about money?}

Remuneration and benefits packages that may be expected by a trainee sales person in the United Kingdom in their mid-20's and with a first degree (BSc/HNC) plus 2 years laboratory experience:

- $£ 12,000-£ 16,000$ basic guaranteed salary

- company car

- bonuses/commission (can be as little as $£ 500$ to well over $£ 5,000$ per year)

- pension/health insurance

- daily subsistence allowance

- home telephone bills/line rental

- car'phone/fax/computer terminal

All trainees can expect full product training and a range of internal/external sales training courses.

view. A good agency does this as the first screening process of a more lengthy employment project, and if the candidate makes a strong impression, their qualities can be sold on to the company concerned. This is to be expected, as trained recruitment consultants usually have a sales and technical background, as well as an indepth knowledge of their clients' personalities and products.

Other preparation for the scientist can include reading relevant books on the subject of sales. An agency will often provide a list of suitable publications, but a visit to the business section of a local library will unearth a wealth of information. One should bear in mind, however, that selling is all about personality, and repeating the literature's message parrot fashion will not impress.

The scientist should also arrange to spend a day with a technical sales representative; this will certainly open the eyes of the prospective sales employee and will, so to speak, kill or cure.

The satisfaction to be gained for scientists by using their technical background for a sales career can be enormous. There is no need to lose touch with new developments within science; indeed commercial people, at the sharp end, have more access to the latest technology, and, as their career grows, can often influence developments for the future.

Ann Pinn is with Delta Consultants, based at The Old Courthouse, Priory Road, St Ives, Huntingdon, Cambridgeshire PE17 4BB, UK.

NATURE · VOL 368 · 31 MARCH 1994 